\title{
Sobre a origem das academias científicas
}

\author{
About the origin of the scientific academies
}

\author{
KLEBER CECON \\ Universidade Estadual Paulista Júlio de Mesquita Filho | Unesp
}

\begin{abstract}
RESUMO O foco do trabalho é uma breve exposição sobre a origem das comunidades, sociedades ou academias denominadas"científicas". O que é uma academia? Quais os tipos de comunidades ou sociedades que se desenvolveram? Quando surgiram as sociedades científicas? O que as define como tal? Este artigo aborda esses assuntos sem pretender dar uma resposta definitiva a essas perguntas. Analisa como começou o uso do termo "academia" na Grécia antiga, perpassa as diversas academias culturais europeias e, finalmente, comenta sobre as academias científicas do século XVII, assim como sobre algumas de suas peculiaridades, como o hermetismo e a especificidade.
\end{abstract}

Palavras-chave academias científicas - sociedades científicas - comunidade científica - publicações científicas - hermetismo.

\begin{abstract}
The main focus of this work is to briefly expose about the origins of the so called "scientific" communities, societies or academies. What is an academy? What kinds of academies or societies were created? When the scientific societies started? What defines them as such? Far from give a definitive answer to these questions, this article considers some possibilities. In doing so, it comments about the origin of the term "academy" in ancient Greece, the cultural European academies, and finally some peculiarities of the scientific societies of the seventeenth-century, like hermeticism and specification.
\end{abstract}

Keywords scientific academies - scientific societies - scientific communities - scientific publications - hermeticism.

\section{Introdução ${ }^{1}$}

Na civilização humana é comum o surgimento eventual de estruturas sociais privativas. Por questões e interesses particulares um determinado grupo de pessoas segrega-se do restante da sociedade, visando alguns objetivos comuns aos seus membros. Algumas dessas microssociedades são de identidade pública enquanto outras são secretas.

Uma academia talvez possa ser definida como uma dessas pequenas sociedades privadas das quais alguns indivíduos, por motivos diversos como mérito, habilidade e/ou indicação, são selecionados para fazer parte dela. № final do século XVIII, Girolamo Tiraboschi definiu academia como uma sociedade de homens eruditos regidos por certas regras às quais eles estão sujeitos e que se reúnem para discutir questões eruditas e que, paralelamente, produzem e depois submetem ao escrutínio de seus colegas o fruto de seus estudos. Os nomes das academias já expressam, de certa forma, seus métodos, objetivos ou estado cultural como é o caso dos lincei (lince), investigandi (pesquisadores), cimento (experimento), traccia (evidência), spioni (espiões), illuminati (illuminados), incogniti (disfarçado), crusca (farelo), secreti (segredo), animosi (corajoso), affidati (confiável) etc..$\underline{ }$ 
0 termo "academia", utilizado pelo mundo ocidental moderno, parece possuir raízes gregas. Na Grécia antiga existia, próxima aos muros de Atenas, a cerca de uma milha de distância, uma região de convivência pública com um bosque, jardins, um ginásio (entre outras construções) e atividades religiosas (como o culto a Atenas) conhecida como Academus ou Hecademus, reverenciado herói grego. Essa região era palco do encontro e debate de sofistas e filósofos com seus discípulos a mais ou menos uma geração antes de Platão se estabelecer por ali. Por volta de 380 a.C. Platão comprou uma propriedade nessa região, provavelmente com o auxílio financeiro de seu amigo Dion. Ele viveu naquela região onde seus discípulos e amigos costumavam visitá-lo e discutiam assuntos filosóficos de sua escola. ${ }^{\circledR}$ Academia, portanto, era o nome da região onde estava localizada essa propriedade de Platão, a instituição conduzida na residência tomou o nome do local em que estava inserida. .5

A academia de Platão pode ser considerada como um excelente exemplo de uma academia da antiguidade. Tendências herméticas posteriores foram responsáveis por diversas associações da academia de Platão com uma seleção baseada no conhecimento matemático. 0 caso clássico é a suposta e famosa inscrição na entrada da academia: "ageômetrètos mèdeis eisitô". ${ }^{6} \mathrm{~A}$ inscrição, traduzida para o português, seria algo como "que não entre aqui ninguém que não conheça geometria". Por mais tentadora que seja essa inscrição, ela parece ter sido criada muitos séculos

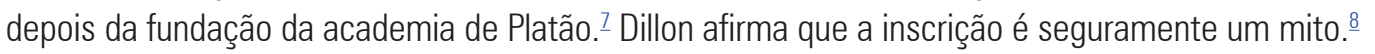

Aristóteles, que era membro da academia de Platão, fundou um tipo de academia também chamada de Liceu. Associações desse tipo existiram por toda Antiguidade e também na Idade Média. Santo Agostinho, depois de seu período maniqueísta, chegou a voltar-se para uma academia, chamada na época de "Nova Academia" ${ }^{\prime \underline{9}}$ cujo princípio básico era o de que probabilidade é tudo o que o ser humano pode esperar no campo do conhecimento. ${ }^{10}$ Associações desse modelo continuaram até a Modernidade e tiveram uma grande importância e sucesso. $\frac{11}{1}$

\section{Hermetismo e universalidade}

Nessa associação de pessoas parece imperar, além do senso de coletividade e cooperação mútua, certo elitismo em participar de um grupo de indivíduos detentores de habilidades distintas dos demais. 0 hermetismo é uma característica muito frequente na orientação, estrutura e até formação de muitos desses grupos e academias da Antiguidade até o Renascimento. Grosso modo, pode-se dizer que o hermetismo é a crença de que certos conhecimentos, corpo de conhecimentos ou informações não devem ser para todos, mas apenas para alguns escolhidos. 0 termo vem de Hermes, o mensageiro dos deuses do Olimpo e divindade da sabedoria, cuja versão egípcia seria Thot e a versão romana seria Mercúrio. $\frac{12}{2}$

O deus egípcio, Thoth, o escriba dos deuses e a divindade da sabedoria, fora identificado pelos gregos com o seu deus Hermes, e algumas vezes recebeu o epíteto 'Três vezes Maior'. Os romanos assumiram esta identificação de Hermes ou Mercúrio com Thoth [...] Uma grande parte da literatura grega foi desenvolvida sob o nome de Hermes Trimegistos. $\frac{13}{14}$

Até hoje o termo hermético tem conotação de fortemente selado ou fechado. Nem sempre a comunicação pública e a discussão de ideias e teorias foram consideradas valores positivos. 0 conhecimento alquímico das grandes arcanas, por exemplo, era algo que, teoricamente, deveria ser ensinado apenas aos escolhidos e iniciados, transmitido de um mestre adepti $\frac{15}{}$ para aprendiz via linguagem decodificada e alegórica. $\frac{16}{}$ Muitos consideravam esse saber um donun Dei, ${ }_{17}^{17}$ ou seja, um presente de Deus para os escolhidos, que não poderia cair em mãos erradas e não deveria ser de domínio público.

Diversos textos com autorias atribuídas a deuses e personalidades de renome atraíam intelectuais que pretendiam atingir verdades sublimes. A Secreta Secretorum, por exemplo, era um conjunto de cartas de Aristóteles para 
seu então aluno, Alexandre Magno, revelando segredos importantes de medicina, astrologia e alquimia e foi uma obra muito conhecida durante a Idade Média. 0 Corpus Hermeticum era um conjunto de 14 tratados datados do segundo século depois de Cristo e traduzidos por Marsilio Ficino no século XV, o qual atribuía a obra a Hermes Trismegisto. 0 Corpus Hermeticum, juntamente com a obra Asclepius, formam um conjunto de forte influência platônica, judaica e até mesmo persa, $\frac{18}{2}$ que são a base para estudos de magia, alquimia e ocultismo na Renascença europeia. Essa tradição hermética é associada a uma noção gnóstica de que existem dois tipos de pessoas: as pessoas simples e ignorantes das massas e os poucos eleitos capazes de discernir as verdades escondidas por trás das palavras e dos símbolos e, portanto, merecedores de serem os detentores de uma verdade que deve ser ocultada das massas..$^{19}$

A atividade hermética pode ser individual, mas também pode se desenvolver dentro de certos grupos ou academias, formando círculos gnósticos e herméticos de influência platônica. Devido ao patronato da poderosa família Médici, as mais famosas e importantes academias renascentistas da Itália foram fundadas na metade do século XV, envolvendo pessoas como Marsilio Ficino, Angelo Poliziano e Pico della Mirandola, às quais as academias platônicas de Florença estavam fortemente associadas. De acordo com Frances Yates, essa estrutura foi a base para todo o movimento acadêmico que, posteriormente, assumiria proporções tais que o século XVI, na Itália, haveria de ser conhecido como 0 "século das academias". 20

As primeiras academias da Renascença italiana, como a academia platônica de Ficino, tiveram um começo muito similar à maioria das academias. Sua organização era bem informal e frequentemente não eram nada mais do que a reunião casual de um grupo de amigos. De acordo com Yates, $\underline{\underline{21}}$ ocorreu um processo gradual de especialização das academias com o tempo. As academias do século XV tinham uma abordagem enciclopédica. 0 hermetismo das mesmas, porém, deslocava o foco das atividades para a busca de verdades antigas perdidas ou codificadas em textos clássicos. Isso fez com que muitas academias, inicialmente, se focassem no estudo de línguas clássicas e em traduções. Muitas delas se especializavam em compreender o simbolismo por trás de antigos textos e imagens.

A grande importância atribuída aos símbolos e representações na Renascença tem uma relação com a filosofia platônica e sua ênfase em formas esotéricas de comunicação, onde verdades ocultas eram escondidas em símbolos e imagens. O acadêmico renascentista era um especialista em mitologia e simbolismo. $\underline{22} \underline{23}$

0 conhecimento de mitologia, fábulas e literatura se tornou lugar comum nessas academias. Isso era devido ao caráter hermético das mesmas, imaginando que os poetas em suas fábulas escondiam verdades sobre a moral, 0 natural e 0 divino. Isso agregou muito valor ao estudo de mitologia durante o período renascentista. $\underline{24} 0$ que se buscava era uma verdade sublime do mundo helênico, uma harmonia universal de união e conglomeração dos homens e um conhecimento completo do mundo. Esse objetivo universal e enciclopédico gerou uma estrutura muito holística na maioria dessas academias. ${ }^{25} 0$ enfoque delas era muito variado, tanto das academias iniciais italianas como, por exemplo, a platônica de Ficino e os Filleleni, ${ }_{26}$ como nas posteriores seiscentistas como a Accademia Fiorentina, 0 Orti Oricellari, a Accademia delle Notti Vaticani e a Accademia degli Infiammati, 27 esta última debatia moral, filosofia da natureza, poesia, retórica e artes. As academias italianas do século XV influenciaram fortemente as francesas do século XVI. $\underline{28}$ Um movimento influenciado pelas primeiras foram as Plêiades, uma academia privada e informal, quase um movimento poético, criado por Pierre de Ronsard (1524-1585), que é impossível separar da criação da Académie de Poésie et de Musique, a primeira academia francesa oficialmente instituída por um decreto real, também conhecida como academia de Baif. $\underline{29}$

A academia de Baif foi uma academia seiscentista francesa com enfoque em música e poesia fundada por Jean-Antoine de Baif (1532-1589). Foi publicamente instituída como academia, com estatuto e documentação oficial, pelo rei Charles IX em 1570.30 0 enfoque universalista e hermético ainda imperava nessas academias. A "música" da academia de Baif não é apenas som, mas num significado amplo é a busca de uma harmonia universal; da união das diferentes religiões ${ }^{31}$ e das diferentes filosofias (como a da lógica aristotélica com a mística platônica ${ }^{32}$ ). 0 mundo teria sido composto como uma grande sinfonia pelo grande artesão. Além disso, a harmonia interna possibilitaria o controle 
das emoções e crescimento moral e espiritual. 0 que se busca nessa música é a proporção perfeita para todas as coisas na convivência humana e na compreensão da natureza e da união com 0 criador..$\underline{33}$ Um grande admirador dessa academia foi o frade mínimo ${ }^{34}$ e pensador setecentista Marin Mersenne (1588-1648). Ele acreditava nos efeitos positivos dessa música, em sentido lato, para fins de elevação moral e para o benefício da cristandade. ${ }^{35}$ Mersenne, personalidade conhecida no século XVII, tinha um enorme círculo de relações pessoais, e manteve correspondência com inúmeros pensadores de seu tempo, tornando praticamente sua vida e seu círculo de relacionamento "um tipo de academia informal e desorganizada" ${ }^{36}$ talvez em parte visando àquela harmonia universal preconizada pela tradição platônica renascentista e, por isso talvez, Yates 0 considere um descendente tardio dessa mesma tradição. ${ }^{37}$

Posteriormente ocorreu com as academias seiscentistas um processo de especialização. 0 século XVII presenciou um fenômeno de desmembramento das mesmas como instituições separadas. ${ }^{38} \mathrm{Na}$ Itália, ainda no final do século $\mathrm{XVI}$, a Accademia della Crusca (1585) ${ }^{39}$ surgiu como uma academia da língua vulgar em oposição às academias que estudavam mais as línguas clássicas, visando o aprimoramento da língua italiana moderna. A Accademia dei Lincei (1600-1630) era uma academia voltada para a filosofia da natureza, assim como a posterior Accademia del Cimento (1657-1667), de forte enfoque experimentalista. Esse processo de especialização pareceu repetir-se em outros países da Europa. Na França, por exemplo, foi fundada a Académie Royale de Peinture et Sculpture, em 1648; a Académie de Danse teve início em 1661 e os encontros da Académie des Inscriptions et Belles Lettres em 1663; a Académie Royale des Sciences, que também é uma academia científica, foi fundada em 1666. A Academié Royale de Musique la Grand Opera) começou em 1669 e já em 1671 também a Académie d'Architeture. 40 Esse processo de especialização das academias, que parece ter sido gradual desde seu início, atingiu o auge no século XVII.

\section{Critérios de cientificidade de uma academia}

As academias especializadas e exclusivas no estudo da filosofia da natureza com teor matemático-experimental parecem ser um fenômeno do século XVII. Não foi apenas no caso da Itália e da França como mostrado. Diferentes sociedades científicas surgiram por toda a Europa.1 No caso da Inglaterra, por exemplo, surgiu a The Royal Society, oficialmente estabelecida como sociedade real de ciências do rei Charles II em 1662. Na Alemanha foram fundadas, entre outras, a Societas Ereunetica, fundada em 1622 por Joachim Jungius (1587-1657) e o Collegium Naturae Curiosorum (ou Accademia Naturae Curiosorum), fundado em 1651, a Collegium Curiosum sive Experimentale, 42 fundada em 1672, e a Academia de Berlin (chamada então de Societas Regia Scientiarum), que foi estabelecida apenas em 1700 e que deve sua existência à perseverança de Gottfried Wilhelm Leibniz. ${ }^{43}$ Esses foram apenas alguns exemplos, de alguns países, do fenômeno das sociedades científicas no século XVII.

De acordo com Yates, ${ }^{44} 0$ início do século XVII foi a era do nascimento das academias científicas modernas. Qual seria a principal diferença dessas academias para que se possa considerá-las científicas? Teriam sido elas as primeiras a estabelecer o estudo dos fenômenos naturais dentro de microssociedades específicas? Na verdade, não. Foi visto que o estudo da filosofia da natureza era muito comum em muitas academias renascentistas e não existe motivo para ter sido diferente com as medievais e antigas.

Todas essas considerações sugerem que as academias francesas do século XVI têm o direito de serem consideradas, pelo menos em um de seus aspectos, academias científicas primitivas - uma ligação entre os longos trabalhos medievais no Timeu, a ampla especulação do neo-platonismo renascentista, e o desenvolvimento das academias científicas organizadas sob o patronato real no século XVII. Os acadêmicos franceses do século XVI se engajaram em filosofia da natureza primordialmente para fins contemplativos, e ela era vista como apenas uma das partes da enciclopédia. $\underline{45} \underline{46}$ 
O movimento acadêmico no século XVI era representativo do espírito livre renascentista; no século XVII os acadêmicos eram usados como instrumentos da ordem e regimentação sob o Absolutismo. Nas academias do século XVI a enciclopédia das artes e das ciências era mantida junta como uma unidade; no século XVII academias específicas foram estabelecidas para diferentes assuntos. $\underline{47} \underline{48}$

Essa abordagem da filosofia natural era uma entre muitas de diversos assuntos, formando um quadro quase enciclopédico. Além disso, o conhecimento da natureza parece ter sido utilizado mais com finalidades de contemplação nas academias seiscentistas. Essa é uma diferença já bem clara das academias científicas setecentistas, cuja atividade de investigação da natureza não repousa em um caráter meramente contemplativo. Acho que é possível estabelecer que um dos pontos que identificariam as academias do século XVI como científicas seria sua especificidade na investigação da natureza.

O segundo ponto importante que pode ser usado como critério para separar as academias do século XVII de academias precedentes foi apontado por Paolo Rossi. Ele afirma que um dos aspectos mais importantes para o surgimento da ciência moderna foi a derrocada do hermetismo e absorção de um comportamento de produção de conhecimento público.49

Para compreender completamente a aparente óbvia diferença entre mágica renascentista e ciência moderna, é necessário considerar não apenas conteúdo e método, mas também a imagem do conhecimento e do erudito [...] deve-se apontar que depois da primeira Revolução Científica, não existiu, nem poderia ter existido, enaltecimento ou uma visão positiva da dissimulação na literatura científica [...] Cientistas trabalhando como uma comunidade realmente podem se comprometer com um segredo, mas esse comprometimento é geralmente imposto sobre eles [...] Para a própria ciência, dentro do mundo científico, segredo tornou-se uma desvantagem. $\frac{50}{51}$

Esta parece ser uma segunda diferença válida entre academias científicas e suas predecessoras. Enquanto a estrutura de muitas academias antigas, medievais e da Renascença tinha um comportamento hermético envolvido, tanto na escolha de seus membros como no compartilhamento de suas informações, as academias científicas $\underline{52}$ têm a característica intrínseca de compartilhar e divulgar seus resultados. Casos de segredo são possíveis, devido a circunstâncias maiores e externas (como a tecnologia de enriquecimento de urânio, por exemplo), mas são vistos como um mal necessário imposto à comunidade científica devido a questões externas, e não como algo que decorra imediatamente do veto ao acesso àquele tipo de informação, que deveria ser entregue apenas às pessoas "certas" e "escolhidas".

Ross ${ }^{i 3}$ insiste na questão de que as sociedades científicas tentavam o máximo possível manterem-se distantes de questões externas. As primeiras academias e sociedades científicas procuravam evitar questões políticas e a intromissão em questões religiosas. Pelo menos em teoria e, de acordo com a letra de seus estatutos, a Accademia dei Lincei não permitia o ingresso de membros que pertencessem a alguma ordem religiosa e baniram de seus assuntos o estudo de quaisquer argumentos que não fossem de ordem matemática e natural, assim como eliminaram assuntos políticos de suas sessões. A Royal Society preferia uma linguagem mais clara, um modo de falar natural, preferindo a linguagem dos artesãos e mercadores à dos escolásticos.

Obviamente Rossi sabia que essa separação não era tão simples. Como uma microssociedade que surge de um ambiente social já estabelecido, é esperado que questões sociais, políticas e econômicas interfiram nas atividades de uma academia. E com relação ao hermetismo, Rossi sabe muito bem que existe forte correlação de diversos autores herméticos da Revolução Científica com atividades desse tipo. Giordano Bruno é um clássico exemplo. ${ }^{54}$ Francis Bacon também se enquadra nesse caso, $\frac{55}{5}$ visto que cinco de seus 39 trabalhos são dedicados (ou citam explicitamente) ao problema de encontrar um conhecimento oculto em mitos e fábulas clássicos. ${ }^{56}$ Nicolau Copérnico defendia que um novo método de calcular o movimento dos corpos celestes poderia ser encontrado no trabalho de filósofos antigos. Ele até apresentou seu trabalho como uma tentativa de reviver as antigas doutrinas de Pitágoras e Filolau..$\underline{57}$ Tycho Brahe viu a astrologia como uma aplicação legítima de seu trabalho científico. Kepler conhecia bem o Corpus Hermeticus e sua teoria de música celestial dos planetas, ele acreditava em uma harmonia mística entre as estruturas geométricas 
e 0 universo. Essas crenças estão profundamente imbuídas, respectivamente, de platonismo renascentista bem ao estilo da Academia de Baif ${ }^{58}$ e de misticismo pitagórico. Alguns trabalhos de Leibniz (e também sua noção de harmonia) parecem ter tido influência da tradição hermética e do lullismo cabalístico. A noção de Harvey de que o coração é o sol de nosso microcosmo também parece refletir temas herméticos dos séculos XV e XVI. A noção newtoniana de espaço como um sensorium Dei revela influência neoplatônica e da cabala judaica.$\underline{59}$ Seguramente, só a forte influência de uma alquimia hermética já seria o suficiente para implicar autores como Newton ${ }^{60}$ e Boyle, $\underline{61}$ e até mesmo o mecanicismo poderia ser encarado como uma renovação do atomismo clássico adaptado ao cristianismo setecentista, purgado de suas tendências ateístas. Jakob Thomasius (1622-1684), orientador de Leibniz e professor da Universidade de Leipzig, escreveu que existia um tipo de pensador em sua época que queria estabelecer novidades por meio do reestabelecimento de ideias antigas já há muito tempo "exiladas". Ele os identificou como novantiqui e muitos deles provavelmente apresentavam tendências herméticas.. 22

Logo, aparentemente ainda no século XVII e na Revolução Científica, exemplos de hermetismo abundam entre seus protagonistas. Que espécie de ausência de hermetismo é essa então que caracteriza as sociedades científicas?

\section{As publicações científicas}

0 que parece é que, mesmo com a adoção de uma postura de divulgação pública de informação no século XVII, continuaram existindo autores herméticos, assim como o hermetismo, mesmo em reconhecidos expoentes da Revolução Científica. Seria muito difícil afirmar o contrário, haja vista todos os casos apresentados. 0 que interessa para este trabalho é que as academias de orientação matemático-experimental que surgiram no século XVII não apresentam um comportamento hermético com relação ao conhecimento que é produzido pela comunidade, enquanto academias. A forma como lidam com o conhecimento não é hermética, independentemente da ação dos indivíduos no processo.

0 único meio de intercomunicação científica no início do século XVII eram as correspondências privadas. Daí a importância da atividade de homens como Mersenne, Peiresc, Collins e Wallis. $\underline{63}$ Ocorreu no início do século XVII uma intensa correspondência entre pensadores da época, muitas delas intermediadas pelo padre Marin Mersenne. A troca de mensagens de Mersenne com seus companheiros era tão intensa que o pequeno quarto em que ele vivia podia ser considerado um dos centros da vida intelectual europeia. Todo intelectual que visitava Paris também visitava Mersenne. Ele tinha uma ampla gama de relacionamentos com pessoas muito relevantes da Revolução Científica (René Descartes mesmo era um amigo íntimo), porém também trocou mensagens com pessoas que nunca encontrou. A própria vida de Mersenne era como uma academia informal e desorganizada. .44 Essa intensa troca de informações no período demonstra uma estrutura longe de hermética. Mesmo que alguns indivíduos tenham tido esse tipo de atitudes, isso não era uma regra geral e nem ocorria no comportamento das academias. Apesar de serem dinâmicas e práticas, as cartas ainda não eram um sistema muito eficiente de troca de informação sobre a filosofia da natureza. Ornstein, por exemplo, afirma que:

A desvantagem dessa forma de comunicação é auto-evidente. Ela depende demais de sentimentos de amizade e hostilidade, e frequentemente de contiguidade geográfica, independentemente se importantes descobertas eram ou não divulgadas para o mundo. O número de disputas relacionadas com descobertas científicas como, por exemplo, entre Torricelli e Pascal, Newton e Leibniz, Hooke e Huygens, provam a insuficiência de tais intercomunicações informais. Visando garantir prioridade, e ao mesmo tempo manter as descobertas em segredo, códigos secretos foram utilizados. $\underline{65} \underline{66}$

A troca de informações por carta parecia ter essa pequena desvantagem. Apesar de ser prática, estava sujeita a intempéries diversas e à proximidade geográfica, envolvia questões de relacionamento pessoal e, além disso, não garantia autoria, o que gerava grande número de desentendimentos. Devido a isso, muitas informações eram codificadas 
no processo de troca de correspondências. Todas essas questões fizeram com que se buscasse uma forma de publicar os dados das atividades experimentais e, com o tempo, as academias passaram a produzir livros visando compartilhar o fruto de suas atividades. A Academia dei Lincei publicou livros como, por exemplo, o Tesoro Messicano (1628-1651). Da mesma forma, seus membros publicavam livros oficiais como membros das academias. Galileu Galilei, quando publicou II Saggiatore (1623), o publicou como um membro da Accademia dei Lincei. Também a Accademia de/ Cimento publicou sua obra Saggi[ㄱ(1667) visando compartilhar seus ensaios. Esse modelo de publicar obras das academias era uma maneira de garantir autorias e publicar resultados.

Outra forma de publicação mais inovadora também foi adotada, e não é surpresa que, ao mesmo tempo em que surgiram as academias científicas, também surgiu o jornalismo científico. Em 1665 Denis de Sallo (1626-1669) publica o primeiro volume do Journal de Sçavans, considerado o primeiro periódico de que se tem notícia. Dennis de Sallo era membro do Parlamento de Paris e era próximo a Colbert $\frac{68}{}$. Sallo tinha o hábito, em suas leituras, de traduzir e armazenar via copistas tudo o que julgasse relevante, e organizou esse material de forma que pudesse obter rapidamente a informação que desejasse, sobre qualquer assunto. Ele percebeu que poderia fazer pelo público o favor que fazia a si mesmo, e submeteu a Colbert um esquema de publicação semanal de interesses gerais. Essa idéia, que nos parece tão natural, foi na época uma revolução. Colbert ficou extasiado com a proposta e Sallo obteve rapidamente o privilégio de editar o material, sob o nome de Jounal des Sçavans. $\underline{69} 0$ primeiro número apareceu em 5 de janeiro de 1665 . Esse periódico tinha diversos focos, como sessões de catálogos e sinopses de livros publicados, obituários de homens famosos e sumários de seus trabalhos, além da publicação de experimentos em física, química, descobertas nas ciências e artes, máquinas inventadas, observações astronômicas, fenômenos meteorológicos e novidades de anatomia animal. Também se publicava decisões de tribunais e universidades, além de acontecimentos do mundo literário. $\underline{70}^{0}$

0 Journal des Savants parece ter sido relativamente eclético em seus assuntos. Um periódico com caráter mais científico, no sentido de ser muito mais especializado em divulgação de dados experimentais, foi o Philosophical Transactions, que era o periódico oficial da The Royal Society of London, a academia de ciência inglesa. 0 primeiro exemplar foi publicado em 1 de março de 1665, ou seja, apenas dois meses depois da primeira edição do Journal des Savants. Um dos primeiros secretários da Royal Society, Henry Oldenburg (1618-1677), foi quem organizou a publicação periódica mensal dos experimentos realizados nas reuniões da sociedade. ${ }^{11}$ Diferentemente do Journal des Savants, seu enfoque era muito mais voltado para publicação de dados e atividades experimentais e o periódico Philosophical Transactions continua sendo editado até os dias de hoje. $\underline{.2}$

É possível dizer que todos os periódicos de orientação científica que se desenvolveram posteriormente foram baseados nesses dois modelos. O Journal des Savants era usado como modelo de periódico de assuntos mais amplos e para um público mais geral e o Philosophical Transactions como padrão para as publicações das sociedades científicas. Logo surgiram outros jornais especializados baseados nesses, podendo ser considerado similar ao modelo francês, por exemplo, o periódico italiano Giornale de Litterati di Roma (1668-1679). Um periódico nos moldes do Philosophical Transactions foi o jornal científico Acta Eruditorum, publicado mensalmente em Leipzig a partir de 1682. $\cdot \underline{73} 0$ Acta Eruditorum foi fruto da dedicação de Otto Mencke (1644-1707), duque da Saxônia e professor de moral e filosofia prática na Universidade de Leipzig. Os artigos eram publicados em latim, não se davam muita importância a eventos e tinha um apelo direto às classes eruditas. Combinando elementos escolásticos tradicionais com a nova filosofia experimental, parecia ter um espírito diferente do Philosophical Transactions, apesar de ter adotado sua forma. Seus temas também incluíam assuntos teológicos, medicina, direito e filosofia experimental. Em seu primeiro volume é possível encontrar trabalhos de Boyle, Sydenham, Denis Papin, Sturm, Borelli, Leibniz, Helvetius, Bernoulli etc. ${ }^{74}$

Ao final do século XVII já era possível afirmar que a cultura de jornais especializados era um formato de sucesso. 0 hábito de obter e publicar informações por meio de artigos em jornais especializados acabou por influenciar a forma como os intelectuais e pensadores lidavam com o conhecimento. 0 próprio Leibniz, aparentemente, influenciado por essa estrutura informacional, preferia publicar seus dados na forma de artigos. Ele publicou apenas um único livro; a Teodiceia. Os outros foram editados e publicados posteriormente, e não existe nenhum livro ou apenas pequeno número deles que possa ser considerado um cânon que apresenta os pontos centrais de sua visão modular. Quando Leibniz 
estava com cerca de 20 anos os jornais especializados estavam começando, e essa mídia era novidade. Ele publicou muito em todos os maiores jornais científicos especializados. A cultura dos jornais pareceu muito adequada a ele, e talvez até mesmo tenha moldado parte da forma como via o conhecimento. $\frac{75}{5}$

Talvez seja importante colocar que essa estrutura de divulgação não estava isenta de eventuais tentativas de segredo ou flertes com o hermetismo por parte de alguns autores. Robert Boyle, por exemplo, chegou a publicar um artigo ${ }^{76}$ no periódico Philosophical Transactions onde descreve que obteve um material com as características do Mercúrio Sófico. ${ }^{ㄲ} 0$ artigo não descreve o processo de preparação, porém Newton ficou tão preocupado com isso que enviou uma carta ao então secretário da Royal Society, Henry Oldenburg, para recomendar a Boyle discrição e prudência para que a preparação do material não fosse divulgada. ${ }^{-78}$ Essa tensão entre divulgação e sigilo pode eventualmente ocorrer $\underline{79}$, mas nesse caso, por exemplo, deve ser mais vista como um medo dos eventuais efeitos nocivos da divulgação da informação do que um não direito das pessoas a ela. De qualquer maneira, esses acontecimentos eram ações individuais e não a base da troca de informações dos periódicos científicos do século XVII. A divulgação da informação para o público geral tornou-se uma virtude, uma qualidade e algo positivo e ao final do século XVII pode-se dizer que essa estrutura se tornou um total sucesso. 0 segredo, que antes era um enaltecimento, tornou-se um prejuízo. $\underline{\underline{80}}$

\section{As academias científicas, o experimentalista e a universidade}

É razoável supor então que existem dois principais diferenciais entre as academias científicas e suas predecessoras: um é a especificidade do foco de atuação (filosofia da natureza com enfoque matemático/experimental) e outro é o tratamento não hermético de suas informações. As academias predecessoras tinham um caráter mais universal e frequentemente hermético em relação às suas informações. Essa nova relação com a informação, aliada à geração de dados experimentais nas academias de enfoque matemático-experimental, acabou tendo como consequência 0 periódico científico.

0 investigador da natureza ou experimentador surge no século XVII como uma nova classe de erudito da sociedade. .11 Essa posição das artes mecânicas foi uma novidade. Nem sempre 0 artesão, 0 construtor manual teve esse status. A diferença entre escravos e homens livres da Antiguidade ecoou como a diferença do trabalho técnico, braçal e artístico para o do homem destinado à contemplação de verdades eternas, sejam filosóficas ou teológicas. Curioso notar que as sete artes liberais do trivium (gramática, retórica e lógica) e do quadrivium (aritmética, música, geometria e astronomia) eram chamadas de "liberais" exatamente porque eram dedicadas e praticadas pelos homens livres (liberi) em oposição ao servo ou escravo que praticava artes mecânicas e manuais. $\underline{82}$ Dentro de uma típica academia e/ou sociedade científica do século XVII, como a Royal Society, por exemplo, pode-se dizer que o status de um experimentalista correspondia ao de um filósofo.

Ao longo do século XVII é que foram desenvolvidos lugares específicos para a atividade experimental. 0 trabalho experimental no início do século XVII não era realizado dentro de universidades e muito menos em lugares específicos para isso. Os laboratórios de alquimia existiam há muitos séculos (nasceram praticamente junto com a alquimia, dada a natureza essencialmente experimental desse tipo de conhecimento), mas eram em sua maioria estabelecidos em casas e locais privativos e individuais. No caso de um laboratório de física, ele sequer existia. Algumas vezes quartos e cozinhas eram usados como local para experimentação. As pesquisas de óptica de Newton foram realizadas em seus alojamentos. Robert Boyle testou a lei da elasticidade dos gases em tubos distribuídos na escadaria no interior de sua casa. No final do século XVII já era possível afirmar que essas estruturas caseiras foram substituídas por laboratórios de química e física em ambiente específico e não individual, mais ou menos de forma embrionária de como existem hoje. $\underline{83} \underline{84}$

A relação das universidades com as academias científicas não foi sempre cordial. As academias não se formaram dentro das universidades, mas fora delas e, frequentemente, em oposição às mesmas. Talvez um dos fatores responsáveis por isso tenha sido a questão do papel da autoridade nessas instituições. ${ }^{85}$ Antes, a leitura de livros e obras clássicas 
de grandes autores era a medida para o estudo da filosofia da natureza. A questão era a posição que certas obras e autores (como, por exemplo, Aristóteles em filosofia natural ou Galeno em medicina) tinham dentro da investigação da natureza. As obras de filosofia natural em Aristóteles como De Caelo, Geratione et Corruptione, Physica, Meteorologica e o De Anima exerciam enorme influência no currículo das universidades europeias, como a Universidade de Paris, $\frac{86}{\text { por }}$ exemplo, ainda no início do século XVII. ${ }^{87}$ Algo que, por sinal, só iria desaparecer completamente das universidades na

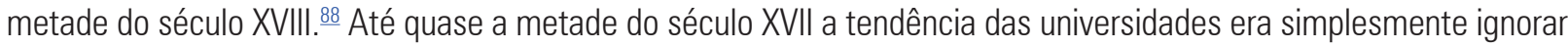
os trabalhos de filosofia experimental. ${ }^{89} \mathrm{~A}$ autoridade de tais textos no período vinha do fato de que eles serviam como lugar comum para a discussão de certos assuntos. Caso alguém quisesse, por exemplo, escrever sobre os corpos celestes, o procedimento apropriado seria compor um comentário do De Caelo..$\underline{0}$

Estabeleceu-se dentro das academias ou sociedades científicas um processo diferente do das universidades com relação ao processo de autoridade. 0 investigador da natureza assumiu nelas um papel ativo e não mais passivo perante a natureza. $\stackrel{91}{0}$ experimentalista constitui autoridade enquanto lê, não mais o livro de um autor clássico, mas 0 verdadeiro livro da natureza que é o mundo, e esse livro foi escrito em outros caracteres, e para lê-lo seriam necessárias novas lentes. A posição do experimentalista executando um experimento, com sua abordagem matemática, em um momento singular e em posição ativa, contrapunha-se enormemente ao modo de análise e obtenção de conhecimento natural presente nas universidades. As universidades não eram abertas para novidades nesse sentido, já que estavam mais para uma estrutura cristalizada e rígida. A educação ainda se mantinha nas mãos da Igreja, que atuava como parte do Estado. Apesar de estarem colapsando, ainda existiam as estruturas de controle medieval das quais dependiam o governo, as leis, a educação e a religião. ${ }^{92}$ Aparentemente reinava dentro das universidades europeias do início do século XVII uma oposição à liberdade de pensamento, como pode ser visto nesse trecho da Ratio Studiorum, obra que guiava a atuação educacional dos jesuítas.

O professor não deve autorizar que sejam sugeridas quaisquer novas opiniões ou discussões; nem mencionar ou permitir que outros mencionem as opiniões de um autor de reputação não conhecida; nem ensinar ou aprender nada contrário às opiniões predominantes de reconhecidos doutores nas escolas. Opiniões falsas e obsoletas não devem ser mencionadas de forma alguma, nem mesmo para refutação, nem se deve deter alongadamente nas objeções dos ensinamentos recebidos. Em filosofia Aristóteles deve sempre ser

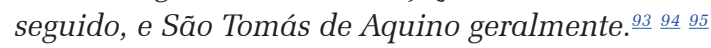

As universidades tiveram pouco ou quase nenhuma atuação dentro da filosofia experimental no início do século XVII. Grande parte dos intelectuais e pensadores que fizeram parte das sociedades científicas ou da Revolução Científica do século XVII não teve filiação alguma com as universidades, apesar de eventualmente terem estudado nas mesmas em sua juventude. .96 Mesmo os membros que não eram totalmente dissociados das universidades ou eram docentes de colégios bem heterodoxos, como Robert Hooke ou Marin Mersenne, respectivamente, no Gresham College e no Collége de France, ou o foram durante um período curto e insignificante de suas vidas, como Denis Papin, ou eram pesquisadores cuja eficiência e proeminências foram devidas às atividades totalmente externas à universidade, como no caso de Newton e Halley. ${ }^{97}$ Galileu foi professor em Pádua e depois em Pisa, mas foi como pensador independente e como filósofo e matemático da corte do grão-duque Cosimo Il que realizou suas atividades de maior destaque, e suas ideias não tiveram fácil aceitação nas universidades.

0 termo novatore foi usado para se referir àqueles indivíduos que desafiavam a ortodoxia aristotélica. 0 termo em inglês usado para os novatores é novelists, o que em português poderia ser traduzido como "novelistas" ou "inovadores". Eles eram vistos como pessoas que tinham ideias novas e estranhas, e eram vistos como à margem do conhecimento formal. Existiam até mesmo listas de novatores. Seu aspecto era muito variado, e na verdade a única coisa que tinham em comum era a rejeição da autoridade de Aristóteles e dos aristotélicos. ${ }^{98}$ Os citados novantiqui, de Thomasius, também eram considerados por ele como novatores. $\underline{99}$

Não é uma coincidência a separação dos experimentalistas das universidades. Aparentemente sua estrutura não comportava a ideia de um agente experimentador ativo da natureza e, devido a sua estrutura fixa e rígida, essa inserção 
e mudança não ocorreram facilmente. Esse é um dos motivos pelos quais as academias científicas se desenvolveram fora das universidades e, muitas vezes, em oposição a elas. A maioria das críticas contra as universidades geralmente eram dirigidas ao conservadorismo de seu sistema. ${ }^{100}$ As sociedades científicas agrupavam os experimentalistas em um único ambiente, agindo conjuntamente, publicando seus resultados, traduzindo livros e coordenando esforços de vários países. A inevitável conclusão é que a universidade não tinha uma estrutura que possibilitasse o desenvolvimento da filosofia experimental, então ela se desenvolveu mais dentro das academias. 101

Ornstein oferece duas citações que colaboram para reforçar ainda mais essa diferença entre as academias e as universidades europeias do século XVII. Uma é de Harnack, a respeito de seu estudo sobre a Academia de Berlin.

As universidades europeias nasceram no auge da Idade Média, e suas instituições correspondiam à atitude medieval de transmissão da totalidade dos conhecimentos numa forma fixa. As academias da Europa pertenceram a uma época que começou na metade do século XVII, e suas instituições são uma expressão do novo espírito que, dali para diante, iria atrelar seu poder aos domínios do pensamento e da vida.102 103

E a outra é de Lexis, historiador das universidades alemãs.

A nova filosofia e ciência da natureza não nasceu dentro dos muros das universidades. O resultado disso era que as universidades não acompanharam o espírito de seu tempo e gradualmente caíram em descrédito. Enquanto nas universidades a velha física e cosmologia escolástica eram ensinadas com estrita aderência aos textos aristotélicos, surgiram externamente a elas, e desprezados por elas, o aprendizado científico e a matemática moderna, que eventualmente levaram a uma completa transformação de nossas concepções do universo. As universidades permaneceram inalteradas, exceto aquelas que foram ocasionalmente chamadas para se levantar contra os invasores. Consequentemente, a filosofia moderna tornou-se um poder hostil às universidades, as quais pareciam antiquadas em vista dos novos ideiais educacionais. 104105

Logo, aparentemente, as universidades que existem hoje parecem ter pouco, ou muito menos similaridades com as universidades medievais ou do início do século XVII do que com as academias ou sociedades científicas do século XVII. Apenas após um longo processo ocorreu a migração da estrutura das academias científicas para dentro das universidades, tornando-as mais próximas da estrutura que conhecemos hoje. ${ }^{106}$ Assim, a estrutura das atuais universidades com base em ensino e pesquisa pode ter sido uma herança formada pela mistura da relação aprendizado e ensino das universidades medievais com o aprimoramento, investigação e divulgação do conhecimento das academias e sociedades científicas do século XVII. Esse modelo misto em que as universidades são também instituições de pesquisa (além de ensino) parece ter se iniciado no século XIX, particularmente na Alemanha. Esse modelo "alemão" que torna o professor universitário também um pesquisador ganhou muita força e se espalhou rapidamente pelo mundo, tornando-se o padrão universitário conhecido hoje. ${ }^{107}$

\section{Considerações finais}

A sociedade humana regularmente se divide em uma série de microssociedades com os mais diversos interesses. As academias que se iniciaram na Grécia Antiga tiveram seu auge no século XVI, que chegou a ser conhecido como 0 século das academias. Elas estavam disseminadas pela sociedade, e tratavam de temas como literatura, linguística, música etc. Aparentemente, no final do século XVI e início do século XVII, começaram a surgir academias que tratavam especificamente da filosofia da natureza. Essa especificação podia ter um tanto um enfoque matemático como experimental. Além disso, tais academias também procederam com um tratamento menos hermético da informação que, apesar de não excluir completamente o hermetismo, acabou por culminar no desenvolvimento de periódicos científicos como o Journal des Savants e o Philosophical Transactions. 
As academias científicas floresceram no século XVII e se multiplicaram por diversos países criando uma tendência irreversível. Academias mais conhecidas como as da região da Itália - Umbria e Toscana (Accademia dei Lincei e Accademia del Cimento), França - Paris (Académie Royale des Sciences) e Inglaterra - Londres (Royal Society of London) tornaram-se um modelo a ser seguido por outras academias e passaram até mesmo a influenciar posteriormente as universidades, sendo que as relações iniciais entre elas não foram necessariamente harmoniosas. É possível perceber até hoje no senso comum a ideia de que a pesquisa científica começou com as universidades quando, na verdade, ela era externa a elas e, em alguns casos, essas instituições até mesmo lhe fizeram oposição.

0 surgimento da pesquisa científica parece estar, na verdade, muito mais atrelado ao surgimento das sociedades científicas do que à universidade. Uma abordagem sociológica do conhecimento científico veria, por exemplo, que 0 surgimento da ciência ocorre com o surgimento das sociedades científicas. Portanto, para se investigar tanto questões epistemológicas de demarcação e identidade como questões históricas de surgimento da ciência, talvez seja mais indicado se voltar a atenção às sociedades ou academias científicas.

\section{Notas e referências bibliográficas}

Kleber Cecon é professor de Filosofia das Ciências Naturais no Departamento de Filosofia da Universidade Estadual Júlio de Mesquita Filho (Unesp), em Marília (SP). Possui formação em Química e em Filosofia. Atua como pesquisador em História e Filosofia da Ciência. Desde seu pós-doutorado vem pesquisando sobre as sociedades científicas. E-mail: kleber.cecon@unesp.br

10 autor gostaria de agradecer ao professor Daniel Garber; ao departamento de filosofia de Princeton University pela infraestrutura e ajuda no desenvolvimento deste trabalho; ao professor Michael Hunter do Birkbeck College pelas valorosas dicas; à bibliotecária Eliana Marciela Marquetis; à Fundação de Amparo à Pesquisa do Estado de São Paulo (Fapesp) pelo apoio financeiro.

2 ROSSI, P. The birth of modern science. Translated by Cynthia De Nardi Ipsen. Oxford: Blackwell, 2001. p. 194-195.

3 GUTHRIE apud DILLON, J. The heirs of Plato: a study of the Old Academy (347-27 BC). New York: Oxford University Press, 2003. p. 6.

4 DILLON, 2003, op. cit., p. 2.

5 Para saber mais sobre a estrutura física da academia de Platão e sua relação como ambiente em que estava inserida, favor consultar DILLON, 2003, op.cit., p. 2-16.

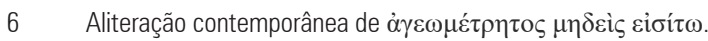

$7 \quad$ KATZ, V. J. A history of mathematics: an introduction. New York: Harper Collins, 1993. p. 48-49.

8 DILLON, 2003, op. cit., p. 96.

9 Para saber mais sobre a relação de Agostinho com os acadêmicos, favor consultar: AUGUSTINE, Saint, Bishop de Hippo. Saint Augustine against the academicians (contra academicos). Translation from the Latin, with an introduction, by Sister Mary Patricia Garvey. Milwaukee, WI: Marquette University Press, 1957. (Mediaeval philosophical texts in translation, n. 2).

10 GARVEY, M. P. Introduction. In: AUGUSTINE, Saint, Bishop de Hippo. Saint Augustine against the academicians (contra academicos). Translation from the Latin, with an introduction, by Sister Mary Patricia Garvey. Milwaukee, WI: Marquette University Press, 1957. (Mediaeval philosophical texts in translation, n. 2). p. 1.

11 YATES, F. A. The French academies of the sixteenth century. London: Routledge, 1988. p. 1.

12 Para saber mais a respeito do hermetismo, favor ver YATES, F. A. Giordano Bruno and the Hermetic Tradition. Chicago: University of Chicago Press, 1979.

13 YATES, 1979, op. cit., p. 2.

14 "The Egyptian God, Thoth, the scribe of the gods and the divinity of wisdom, was identified by the Greeks with their Hermes, and sometimes given the epithet of "Thrice Great". The Latins took over this identification of Hermes or Mercurius with Thoth [...] A large literature in Greek developed under the name of Hermes Trismegistus" (Yates, 1979, op. cit., p. 2).

150 adepti é o detentor do segredo da Lapis Philosophorum (Pedra Filosofal).

16 Para um bom exemplo de codificação e decodificação de um texto alquímico, favor ver NEWMAN, W. R. Gehennical Fire: the life of George Starkey, an American alchemist in the scientific revolution. Cambridge, MA: Harvard University Press, 1994. p. 115-169.

17 Donum Dei (latim), presente de Deus. Para saber mais sobre o conhecimento alquímico como um presente de Deus e a relação da alquímica com busca da perfeição, favor ver NEWMAN, W. R. Promethean ambition, alchemy and the quest to the perfect nature. Chicago: University of Chicago Press, 2004.

18 YATES, 1979, op. cit., p. 3.

19 ROSSI, 2001, op. cit., p. 19.

20 YATES, 1988, op. cit., p. 1. 
23 "The great importance attributed to emblems and devices in the Renaissance has a relationship to the Platonic philosophy with its emphasis on esoteric forms of statement, on the truths hidden in symbols and images. The Renaissance academician was an expert on mythology and symbolism" (YATES, 1988, op. cit., p. 10).

$24 \quad$ Idem, p. 131.

25 Idem, p. 9, 42.

26 Um grupo que girava em torno de Aldo Manuzio (1449-1515) em Veneza, tinha estrutura similar à academia de Ficino.

27 A Accademia Fiorentina foi fundada em Florença em 1540. 0 Orti Oricellari era um grupo que se encontrava pelos jardins de Florença no início do século XVI, discutia filosofia, retórica e política e tinha tradição acadêmica. A Accademia degli Infiammati foi fundada em Pádua em 1562. A Accademia delle Notti Vaticani foi fundada em Roma em 1562, e era uma academia do movimento de contra-reforma, com ênfase em retórica, arte e religião. Encontravam-se quatro vezes por semana e, como o nome indica, apenas durante a noite no Vaticano. Alguns membros tinham curiosos pseudônimos nas reuniões, como "Caos", no caso do cardeal Borromeo. Todas continuavam com um forte direcionamento filológico e retórico.

28 YATES, 1988, op. cit., p. 13.

29 Idem, p. 14

$30 \quad$ Idem, p. 19

31 YATES (1988, p. 307) comenta que até mesmo a obsessão de Leibniz em unir católicos e protestantes tem relação com isso.

32 Para Pico de la Mirandola, esse teria sido um dos pontos mais importantes de seu trabalho (YATES, 1988, op. cit., p. 111).

33 Idem, p. 9, 24.

34 Um frade mínimo é um frade que pertence à Ordem dos Mínimos, uma ordem religiosa católica mendicante, criada por São Francisco de Paula (1416-1507) no século XV, na Itália.

35 YATES, 1988, op. cit., p. 40-41, 64 .

$36 \quad$ Idem, p. 285.

37 Idem, p. 288

38 Para saber mais a respeito, favor consultar YATES, 1988, cap. 12: "Connections of the sixteenth-century french academies with those of the seventeenthcentury", p. 275-316.

39 Essa academia também se iniciou como uma reunião informal de amigos e inicialmente o grupo chamava-se brigata dei crusconi (brigada do farelo). 0 nome havia sido escolhido para se distanciar da famosa Accademia Fiorentina, por considerá-la elitista e pedante, cujo enfoque linguístico seria mais o de línguas clássicas. Os participantes preferiam se conectar a estudos da linguagem comum e vulgar, que consideram mais próximas do povo. A primeira reunião como academia ocorreu em 26 de janeiro de 1583, porém, a cerimônia oficial de abertura foi apenas em 25 de março de 1585. A academia existe até hoje; para mais informações sobre ela, favor consultar < http://www.accademiadellacrusca.it/en/accademia/history/origins-and-foundation>. Acesso em: 21 abr. 2017

40 YATES, 1988, op. cit., p. 275.

41 Um estudo clássico sobre as comunidades, sociedades ou academias científicas do século XVII pode ser encontrado em ORNSTEIN, M. The role of scientific societies in the seventeenth century. Chicago: Chicago University Press, 1928.

42 Fundado por Christopher Sturm que foi professor de matemática e física por 34 anos na Universidade de Altdorft, era considerada uma instituição progressiva. Sturm esteve presente em sessões da Accademia del Cimento e decidiu criar uma nova academia com estrutura e métodos similares. Assim, convidou simpatizantes de atividades experimentais, a maioria deles seus alunos. Ele basicamente usou um laboratório de física privativo que tinha em sua residência (ORNSTEIN, 1928, op. cit., p. 175).

43 ORNSTEIN, 1928, op. cit., p. 177.

44 YATES, 1988, op. cit., p. 103.

45 Idem, p. 104

46 "All these considerations suggest that the sixteenth-century French academies have a right to be regarded as, in one of their aspects, early scientific academies - links between the long medieval labours on the Timaeus, the wide speculations of Renaissance Neo-Platonism, and the seventeenthcentury development of the organized scientific academy under royal patronage. The sixteenth-century French academicians engaged in natural philosophy primarily for contemplative ends, and regarded it as only a part of the encyclopaedia" (Idem, p. 104).

$47 \quad$ Idem, p. 311

48 "The academic movement in the sixteenth century stood for the free Renaissance spirit; in the seventeenth-century the academies are used as instruments of order and regimentation under Absolutism. In the sixteenth-century academies the encyclopaedia of the arts and sciences was held together as a unit; in the seventeenth-century, separate academies are set up for different subjects" (Idem, p. 311).

49 Para saber mais a respeito, favor consultar ROSSI, 2001, op. cit., cap. 2: "Secrets", p. 18-28.

$50 \quad$ Idem, p. 28.

51 "To fully understand the seemingly obvious difference between Renaissance magic and modern science, one must consider not only content and method, but also the image of knowledge and of the scholar [...] it should be pointed out that after the first Scientific Revolution, there was not, nor could there have been, praise for or a positive view of dissimulation in the scientific literature [...] Scientists working as a community may indeed pledge secrecy, but the pledge is usually imposed upon them [...] For science itself, and within the scientific world, secrecy became a liability" (ROSSI, 2001, op. cit., p. 28). Idem. 
Idem, p. 23-24.

54 YATES, 1979, op. cit.

55 Para saber mais, consultar ROSSI, P. Francis Bacon: from magic to science. Translated by Sacha Rabinovitch. London: Routledge and Kegan Paul, 1968.

56 ROSSI, 1968, op. cit., p. 80.

57 ROSSI, 2001, op. cit., 56.

58 Impossível não fazer um comentário interessante sobre um caso em que a relação análoga entre música e ciência da natureza teve um encontro relativamente bem-sucedido. 0 químico John Alexander Reina Newlands (1837-1898), de descendência italiana por parte de mãe, baseado na relação entre as notas musicais na qual a oitava nota repete a primeira (regra conhecida como "lei das oitavas"), propôs que os elementos químicos deveriam seguir um padrão parecido, e os elementos deveriam repetir suas propriedades a cada oito elementos em uma sequência crescente organizada por peso atômico. Irregularidades com essa ordenação fizeram com que a teoria de Newlands não ganhasse muito crédito junto à comunidade de cientistas de sua época. Algum tempo depois Mendeleev (desconhecendo a teoria de Newlands) propôs a tabela periódica dos elementos, utilizando também a lei das oitavas, mas Mendeleev assumiu que as irregularidades eram devidas a elementos ainda não descobertos, e que foram efetivamente descobertos depois, fazendo sua teoria ganhar força. A relação das oitavas das notas musicais com os elementos se deu por uma ideia de que a mesma harmonia que rege a música também rege o mundo físico, num estilo muito similar ao da Academia de Baif. Para saber mais, consulte o site da Royal Academy of Chemistry: $<$ http://www.rsc.org/education/teachers/resources/periodictable/pre16/develop/newlands.htm>. Acesso em: 21 abr. 2017.

59 ROSSI, 2001, op. cit., p. 26.

60 Para saber mais sobre alquimia e hermetismo em Isaac Newton, favor ver DOBBS, B. J. T. The foundation of Newton's alchemy, or 'The Hunting of the Greene Lyon'. New York: Cambridge University Press, 1983. Independente da questão da autoria da obra De Clavis, Dobbs faz um excelente trabalho mostrando o lado alquímico de Newton. No caso da autoria, Dobbs afirma ser o De Clavis uma obra de Newton; isso suscitou críticas por parte de Newman que acredita que o tratado foi escrito por Philalethes. Para mais informações ver CECON, K. A relação entre a filosofia mecânica e os experimentos alquímicos em Robert Boyle. Campinas: Unicamp/Centro de Lógica, Epistemologia e História da Ciência, 2011. (Coleção CLE, v. 61). p. 28.

61 Para mais informações sobre a alquimia e hermetismo em Robert Boyle, favor ver PRINCIPE, L. M. The aspiring adept: Robert Boyle and his alchemical quest. Princeton: Princeton University Press, 1998.

62 THOMASIUS, J. Adversus Philosophos Libertinos. In: THOMASIUS, J. Dissertationes LXIII. Halæ Magdeburgicæ, impensis Johannis Friderici Zeitleri, 1693. p. $438-439$

63 ORNSTEIN, 1928, op. cit., p. 198.

64 YATES, 1988, op. cit., p. 284-285

65 ORNSTEIN, 1928, op. cit., p. 199

66 "The unreliability of this form of communication is self-evident. It depended too much on friendly or hostile feeling, and at times on geographical contiguity, whether or not important discoveries reached the world. The numerous quarrels regarding scientific discoveries, as for instance between Torricelli and Pascal, Newton and Leibniz, Hooke and Huygens, best prove the insufficiency of such informal intercommunications. In order to secure priority while keeping discoveries secret, ciphers were used" (Idem, p. 199).

67 A ideia era mostrar alguns exemplos dos experimentos feitos pela Accademia del Cimento. A obra foi lançada em Florença, em 1667. Para saber mais a respeito favor consultar: MIDDLETON, K. W. E. The experimenters: a study of the Accademia del Cimento. Baltimore: The Johns Hopkins Press, 1971.

68 Ministro de Estado e das finanças do rei da França Luís XIV, Jean-Baptiste Colbert (1619-1683).

69 0 Journal des Sçavans manteve esse nome de 1665 até 1790, de 1971 até 1830 foi denominado de Journal des Savans, e depois disso, Journal des Savants. Esta última forma é a que será adotada daqui por diante.

70 ORNSTEIN, 1928, op. cit., p. 199-200.

71 Idem, p. 124-125.

72 Para mais informações sobre as atividades e estruturas atuais do periódico, favor consultar sua homepage: < http://rstl.royalsocietypublishing.org/>. Acesso em: 21 abr. 2017.

73 A partir de então também conhecido como Acta Leipsiensia.

74 ORNSTEIN, 1928, op. cit., p. 202-205.

75 GARBER, D. Thinking in the age of learned journal: Leibniz's modular philosophy. In: LI, W. (ed.). Für unser Glück oder das Glück anderer: Vorträge des X Internationalen Leibniz-Kongresses. Hildesheim: Georg Olms, 2017. v. 6, p. 195-204.

76 BOYLE, R. Of the incalescence of quicksilver with gold. Philosophical Transactions, v. 10, p. 515-533, 1675.

770 Mercúrio Sófico seria uma das etapas para a obtenção da Pedra Filosofal. Para saber mais especificamente sobre isso, favor conferir NEWMAN, W. R.; PRINCIPE, L. M. Alchemy tried in the fire: Starkey, Boyle and the fate of Helmotian Chymistry. Chicago: University of Chicago Press, 2002. Cap. 1.

78 NEWTON, I. Letter from Newton to Henry Oldenburg, dated 26 April 1676. In: The Newton Project. Oxford: Oxford University, 2017. Disponível em: < http:// www.newtonproject.ox.ac.uk/view/texts/normalized/NATP00268 >. Acesso em: 19 jul. 2017.

79 Para saber mais, ver ALFONSO-GOLDFARB, A. M. Uma suposta contradição na ciência inglesa do século XVII: divulgação e sigilo. Discurso, n. 31, p. 347363, 2000.

80 ROSSI, 2001, op. cit., p. 28.

$81 \quad$ Idem, p. 22.

82 Idem, p. 15

83 ORNSTEIN, 1928, op. cit., p. 4-5.

84 Obviamente esse não é o caso de laboratórios astronômicos para observações de corpos celestes que, devido à sua associação anterior com a astrologia, 
existiram muitos séculos antes dos laboratórios de física.

85 Para saber mais, favor ver DEAR, P. Totius in verba: rhetoric and authority in the early Royal Society. Isis, v. 76, n. 2, p. 145-161, June, 1985.

86 A universidade de Paris é um exemplo bastante representativo a respeito do comportamento das universidades com relação à filosofia natural. Para saber mais favor consultar BROCKLISS, L. W. B. Aristotle, Descartes and the New Science: natural philosophy at the University of Paris, 1600-1740. Annals of Science, v. 38, n. 1, p. 33-69, 1981.

87 BROCKLISS, 1981, op. cit., p. 38

88 Idem, p. 34.

89 Idem, p. 43.

90 DEAR, 1985, op. cit., p. 150.

91 Idem, p. 157.

92 "The heir of Renaissance, it felt the spirit of freedom and mastery but also the rude shocks and clashes which marked the collapse of those medieval controls upon which it still depended in government, law, education and religion." Citado por LOEMKER, L. E. Introduction: Leibniz as philosopher. In: LEIBNIZ, G. W. Philosophical papers and letters. Translated and edited, with an introduction by Leroy E. Loemker. 2.ed. Dordrecht: D. Reidel, 1976. p. 2.

93 ORNSTEIN, 1928, op. cit., p. 215.

94 Citação oriunda da Ratio Studiorum obtida na Enciclopédia Britânica (2ª edição), "Jesuítas" apud ORNSTEIN, 1928, op. cit., p.215.

95 "The teacher is not to permit any novel opinions or discussions to be mooted; nor to cite or allow others to cite the opinions of an author not of known repute; nor to teach or suffer to be taught anything contrary to prevalent opinions of acknowledge doctors current in the schools. Obsolete and false opinions are not to be mentioned at all even for refutation nor are objections to received teaching to be dwelt on at any length. In philosophy Aristotle is always to be followed and St. Thomas Aquinas generally" (ORNSTEIN, 1928, op. cit., p. 215).

96 É o caso de Bacon, Grew, Boyle, Flamsteed, Willoughby (na Inglaterra); Huygens, Leeuwenhoek, Swammerdam, Van Helmont (na Holanda); Hevelius, Leibniz, Kepler, Guericke (na Alemanha); Descartes, Pascal, Mariotte, Lémery (na França) etc.

97 ORNSTEIN, 1928, op. cit., p. 257.

98 GARBER, D. Why the Scientific Revolution wasn't a scientific revolution, and why it matters. In: RICHARDS, R. J.; DASTON, L. (eds.). Kuhn's Structure of Scientific Revolutions at fifty: reflections on a science classic. Chicago: Chicago University Press, 2016. p. 137-138.

99 THOMASIUS, J. Adversus Philosophos Novantiquos. In: THOMASIUS, J. Dissertationes LXIII. Halæ Magdeburgicæ, impensis Johannis Friderici Zeitleri, 1693a. p. 469.

100 ORNSTEIN, 1928, op. cit., p. 258.

101 Idem, p. 260-261.

102 HARNACK apud ORNSTEIN, 1928, op. cit., p. 261.

103 "The European universities were born at the high tide of the Middle Ages, and their institution corresponded to the medieval attitude of transmitting the sum of knowledge in fixed form. The Academies of Europe belong to the epoch which begins in the middle of seventeenth century, and their institutions are an expression of the new spirit which was thenceforth to attain its power in the realm of thought and life" (Idem, p. 261).

104 LEXIS apud ORNSTEIN, 1928, op. cit., p. 261.

105 "The new philosophy and natural science was not born within the walls of the universities. The result of this fact was that the universities lagged behind the spirit of the time and gradually fell into disrepute. While at the universities the old scholastic physics and cosmology was lectured upon in close adherence to the Aristotelian text, there arose outside and scorned by them, modern mathematical and scientific learning, which eventually led to a complete transformation of our conception of the universe. The universities remained unaffected except that they felt occasionally called upon to rise in defense against the invaders. Hence modern philosophy grew into a power hostile to the universities, which seemed superannuated in view of the newer educational ideals" (Idem, p. 261).

106 ORNSTEIN, 1928, op. cit., p. 262.

107 CLARK, W. Academic charisma and the origins of the research university. Chicago: University of Chicago Press, 2006.

[Recebido em Maio de 2020. Aceito para publicação em Março de 2021.] 